\title{
Overlapping Representation of Primary Tastes in a Defined Region of the Gustatory Cortex
}

\author{
Max L. Fletcher, ${ }^{1}$ M. Cameron Ogg, ${ }^{1} \odot$ Lianyi Lu, ${ }^{1}$-Robert J. Ogg, ${ }^{2}$ and John D. Boughter, Jr. ${ }^{1}$ \\ ${ }^{1}$ Department of Anatomy and Neurobiology, University of Tennessee Health Science Center, Memphis, Tennessee 38163, and ${ }^{2}$ Department of Radiological \\ Sciences, St. Jude Children's Research Hospital, Memphis, Tennessee 38105
}

Both physiological and imaging approaches have led to often-disparate conclusions about the organization of taste information in gustatory cortex (GC). In this study, we used neuroanatomical and imaging approaches to delineate the likely area of insular cortex given to gustatory function and to characterize taste responses within this delineated area in female and male C57BL/6J mice. Anterograde tracers were injected into the taste thalamus (the medial parvicellular portion of the ventral posterior medial division, VPMpc) of mice and the thalamic terminal field was investigated across the cortex. Working within the delineated area, we used two-photon imaging to measure basic taste responses in $>780$ neurons in layer $2 / 3$ located just posterior to the middle cerebral artery. A nonbiased, hierarchical cluster analysis revealed multiple clusters of cells responding best to either individual or combinations of taste stimuli. Taste quality was represented in the activity of taste-responsive cells; however, there was no apparent spatial organization of primary taste qualities in this region.

Key words: gustatory cortex; insular cortex; taste; taste coding

\section{Significance Statement}

Recent studies investigating taste coding within the gustatory cortex have reported highly segregated, taste-specific regions containing only narrowly tuned cells responding to a single taste separated by large non-taste-coding areas. However, focusing on the center of this area, we found a large number of taste responsive cells ranging from narrowly to broadly responsive with no apparent local spatial organization. Further, population analysis reveals that activity in the neuronal population in this area appears to be related to measures of taste quality or hedonics.

\section{Introduction}

The gustatory cortex (GC) plays an important role in the generation and maintenance of taste-related behaviors, including neophobia, taste aversion, and other types of associative leaning (Braun et al., 1972; Lin et al., 2009; Samuelsen et al., 2012; Schier et al., 2014; Schier et al., 2016). Underlying these processes, the response properties of cortical neurons may relate to the principle taste quality of chemical stimuli, and/or their hedonic value (Yamamoto et al., 1985a, 1985b; Katz et al., 2001; Jezzini et al., 2013). The primary gustatory cortical area is organized within the

Received March 8, 2017; revised May 25, 2017; accepted June 23, 2017.

Author contributions: M.L.F. and J.D.B. designed research; M.L.F., L.L., and J.D.B. performed research; M.L.F., M.C.O., R.J.O., and J.D.B. analyzed data; M.L.F. and J.D.B. wrote the paper.

This work was supported by the National Institute on Deafness and Other Communication Disorders-National Institutes of Health (Grant 015202 to M.L.F. and J.D.B.) and the Pew Biomedical Scholars Program (M.L.F.). We thank Stephanie Staszko and Joseph Callaway for assistance with aspects of this research.

The authors declare no competing financial interests.

Correspondence should be addressed to Max L. Fletcher, Department of Anatomy and Neurobiology, University of Tennessee Health Science Center, 885 Monroe Ave., Memphis, TN 38163. E-mail: mfletch4@uthsc.edu.

DOI:10.1523/JNEUROSCI.0649-17.2017

Copyright $\odot 2017$ the authors $\quad 0270-6474 / 17 / 377595-11 \$ 15.00 / 0$ insular cortex, which in rodents is externally located on the ventral lateral brain surface bisected by the middle cerebral artery (MCA) (Norgren and Wolf, 1975; Kosar et al., 1986a, 1986b; Cechetto and Saper, 1987; Accolla et al., 2007; Chen et al., 2011; Kida et al., 2015). However, there is debate concerning the topography of GC: that is, whether taste-responsive neurons are spatially arranged or grouped in meaningful ways.

Previous studies in anesthetized rats using physiological or intrinsic imaging techniques indicated that, whereas basic taste stimuli tended to evoke distinctive spatial patterns across the GC, there was substantial overlap to the point that no one area was specific to a particular taste quality (Yamamoto et al., 1985b; Accolla et al., 2007). A similar finding was described in humans using fMRI (Schoenfeld et al., 2004). These findings contrast with a recent 2-photon (2P) imaging study in mice (Chen et al., 2011) in which large clusters of neurons responding only to a single taste quality, including bitter-, salty-, sweet-, and umami-specific groupings, were separated by sparsely responsive regions across the cortical surface. Surprisingly, no "sour" or acid-best region was found, a finding also in conflict with other cortical taste studies. Interestingly, there is evidence that spatial neuronal het- 
erogeneity in present in some other sensory cortices. For example, in mouse piriform (olfactory) cortex, odorants of different classes evoke responses in overlapping distributions of cells (Stettler and Axel, 2009). In layer II/III of mouse somatosensory cortex, whisker receptive fields are, to a degree, overlapping and scattered among columns (Clancy et al., 2015).

To gain further insight into the significance of spatial patterns of taste quality, we used $2 \mathrm{P}$ imaging techniques to image taste responses to basic stimuli in an area of GC in mice immediately posterior to the MCA. This area was chosen due to the greatest probability of overlap among taste qualities based on the rat studies mentioned above. We used a virally expressed calcium reporter, GCaMP6s, shown to be sensitive enough to detect single action potentials from cortical cells in vivo with near $100 \%$ reliability (Chen et al., 2013). All recordings were performed from imaging windows located within an anatomically determined region of GC delineated by the MCA and bifurcation of the caudal rhinal vein. Because the gustatory region of insular cortex can also be defined by taste thalamic input (Cechetto and Saper, 1987; Kosar et al., 1986b; Allen et al., 1991; Shi and Cassell, 1998; Nakashima et al., 2000), we investigated anterograde labeling in this region after tracer injection into the gustatory subnucleus of the thalamus (the medial parvicellular portion of the ventral posterior medial division, $\mathrm{VPMpc}$ ), including in some of the mice used for $2 \mathrm{P}$ imaging.

\section{Materials and Methods}

Animals and imaging surgery. Adult male and female C57BL/6J mice (The Jackson Laboratory) were used. All experimental protocols were approved by the University of Tennessee Institutional Animal Care and Use Committee. Mice were anesthetized with urethane $(2 \mathrm{mg} / \mathrm{kg}$, i.p. $)$. To reduce nasal secretions, mice also received intraperitoneal injections of the blood-brain barrier-impermeant muscarinic receptor antagonist methyl scopolamine at $0.05 \mathrm{mg} / \mathrm{kg}$. Once mice were fully anesthetized, a tracheotomy was performed by inserting and securing a small piece of polyethylene (PE) tubing into the trachea. Mice were then placed in a custom stereotaxic apparatus. The skin overlying the dorsal skull was removed and a head bar was attached using dental cement. The head of the animal was then tilted 90 degrees to allow for installation of the optical imaging window. To expose GC, a small incision was made between the ear and eye. Portions of the masseter and temporalis muscles were cut away. The temporal portion of the zygomatic arch was removed to expose the lateral surface of the skull. The skull overlying the intersection of the MCA and rhinal veins was removed using a dental drill to create a small $(\sim 2 \times 2 \mathrm{~mm})$ window. The surface of the brain was flushed with Ringer's solution, covered with a $1 \%$ agarose solution, and topped with a glass coverslip. The coverslip was fixed into place with dental cement to create a small well. After collection of imaging data, permanent ink was applied to the brain surface and, in one mouse, an iontophoretic injection of $5 \%$ Fluorogold was made into the cortex at the recording site (these procedures were used to aid histological reconstruction). Mice were transcardially perfused with $4 \%$ paraformaldehyde and brains were removed, postfixed, cryoprotected, and subsequently cut into coronal sections $(40 \mu \mathrm{m})$ and examined for fluorescent labeling. In 2 mice, serial sections were examined microscopically with respect to the surface ink (data not shown); from these sections, the MCA was estimated to be located $\sim 1.0 \mathrm{~mm}$ anterior to bregma, a level corresponding to images 44-45 of the P56 Coronal Reference Atlas, part of the Allen Brain Atlas (ABA; http://www.brain-map.org/).

Viral transfection and tracing. For viral transfections, mice were anesthetized with ketamine/xylazine (100 and $10 \mathrm{mg} / \mathrm{kg}$, i.p., respectively) and placed into a stereotaxic head holder. For each animal, $\sim 500 \mathrm{~nL}$ of AAV1.Syn.GCaMP6s (Penn Vector Core) was infused via picospritzer into the insular cortex [injection pipette was placed relative to bregma: anterior-posterior (AP): $+1.5 \mathrm{~mm}$, lateral: $3.7 \mathrm{~mm}$, depth: $2.1 \mathrm{~mm}$ ] through a craniotomy. After infusion, mice were allowed to recover in their home cages for at least 3 weeks before imaging. In some mice, $450 \mathrm{~nL}$ of an viral anterograde tracer (AAV1.CB7.CI.mCherry) was infused into the gustatory area of the thalamus (pipette was placed relative to bregma: AP: $-1.8 \mathrm{~mm}$, lateral: $0.6 \mathrm{~mm}$, depth: $4.2 \mathrm{~mm}$ ), which is located within the VPMpc. Additional thalamic tracing experiments were performed using the anterograde tracer MicroRuby dextran (10\%, $3000 \mathrm{MW} ; 100-200 \mathrm{~nL})$ infused into the VPMpc. In all cases, examination of injection sites revealed that tracers (either AAV or MicroRuby) were found in VPMpc. However, because the gustatory region is relatively small, in nearly all cases, tracers spread somewhat into adjacent regions, especially VPM and the dorsally located parafasicular thalamic nucleus.

Tastant delivery. Once mice were situated under the microscope, the oral cavity was gently held open via a loop of suture placed over the lower incisor. Whole-mouth stimulation with water and stimuli representing four basic taste qualities ( $0.5 \mathrm{M}$ sucrose, $0.3 \mathrm{M} \mathrm{NaCl}, 0.02 \mathrm{M}$ citric acid, and $0.01 \mathrm{M} \mathrm{QHCl}$, presented at room temperature) was delivered through a small length $(8 \mathrm{~mm})$ of PE 160 tubing with its opening placed $\sim 2 \mathrm{~mm}$ into the mouth and $2 \mathrm{~mm}$ above (but not touching) the tongue. This tubing was connected to a manifold, which allowed for switching between water and solutions. Preliminary experiments with methylene blue dye indicated that this fluid delivery method bathes both the dorsal surface of the tongue (including as far back as the posterior tongue taste papillae), as well as the hard and soft palate; however, it is not certain if the posterior taste buds, located within trench-like papillae, are optimally stimulated. During trials, mice received a constant flow (rate $=0.25 \mathrm{ml} / \mathrm{s}$ ) consisting of an $8 \mathrm{~s}$ water presentation, a $10 \mathrm{~s}$ tastant presentation, and a $12 \mathrm{~s}$ water rinse. After the trial, the oral cavity was rinsed with water for an additional $20 \mathrm{~s}$ and then allowed to recover for $1.5 \mathrm{~min}$ before the next trial. Stimuli were presented in random order.

Optical imaging and analysis. Imaging was performed on a Zeiss 7MP 2-photon microscope equipped with a Zeiss $20 \times$ objective. Fluorescence images were collected at $2-4 \mathrm{~Hz}$ at $512 \times 512$ pixel resolution. Imaging regions ranged from 200 to $500 \mu \mathrm{m}^{2}$. Individual cells could easily be identified in resting fluorescence images. ROIs were manually drawn around all cells within an imaging region and raw fluorescence traces for the entire $40 \mathrm{~s}$ of each trial were collected offline using ImageJ.

Immunocytochemistry. Intraoral (IO) cannulas were affixed to the skull in some anesthetized mice after thalamic tracer (MicroRuby) injection. Polyethylene tubing was inserted through the right buccal mucosa, led along the lateral surface of the skull, and secured to the skull using dental acrylic. Three days after surgery, mice underwent an adaptation procedure, receiving distilled water through the $\mathrm{IO}$ cannula $(0.1 \mathrm{ml} / \mathrm{min}$ for $15 \mathrm{~min})$ using a syringe pump in a round Plexiglas test chamber. After 3 consecutive days of this adaptation procedure, mice were infused $\mathrm{IO}$ with $1.5 \mathrm{ml}$ of $0.003 \mathrm{M} \mathrm{QHCl} \mathrm{using} \mathrm{the} \mathrm{same} \mathrm{methods} \mathrm{and} \mathrm{rate} \mathrm{as} \mathrm{the} \mathrm{adaptation} \mathrm{procedure.}$ Two hours after the onset of IO stimulation, mice were anesthetized with ketamine/xylazine (100 and $10 \mathrm{mg} / \mathrm{kg}$, i.p., respectively) and transcardially perfused with $4 \%$ paraformaldehyde. The brains were removed, postfixed, and cryoprotected; coronal sections of the brain were cut serially using a freezing microtome. Antigen expression, including c-Fos, was assessed using standard immunohistochemical procedures, with a rabbit polyclonal anti-cFos antibody (sc-52, Santa Cruz Biotechnology, RRID:AB_10609634); M2type muscarinic acetylcholine receptors were labeled using a rat monoclonal anti-M2 antibody (MAB 367, Millipore, RRID:AB_94952). Primary antibody labeling was visualized with either fluorescent or nonfluorescent secondary antibodies (Savchenko and Boughter, 2011; Tokita et al., 2014; see our previous papers for detailed methods). Microscope sections were imaged using either a Leica DMRXA2 microscope equipped with a digital camera and imaging software or with a confocal microscope (Zeiss 710).

Brief-access taste behavior. Water-restricted C57BL/6J mice $(n=7)$ were tested in a Davis MS-160 contact lickometer with a panel of taste stimuli ( $0.5 \mathrm{~m}$ sucrose, $0.3 \mathrm{M} \mathrm{NaCl}, 0.02 \mathrm{M}$ citric acid, $0.01 \mathrm{M} \mathrm{QHCl}$ ) and water. This method involved $2 \mathrm{~d}$ of training with water only and $2 \mathrm{~d}$ of testing; procedures were based on our previous studies (St John and Boughter, 2009; Saites et al., 2015). On the 2 test days, mice received $185 \mathrm{~s}$ trials divided into 3 blocks consisting of a single presentation of each tastant and 2 presentations of water. Stimuli were ordered randomly within each block. 
Experimental design and statistical analysis. C57BL/6J mice of both sexes were used in these studies based on availability (in our previous studies of taste and licking behavior with this strain we have not detected effects of sex: Boughter et al., 2005, 2007). For 2P imaging, we collected taste responses from 7 adult C57BL/6J mice ( 1 female, 6 male). Analysis was conducted on 783 taste-responsive cells $(204,207,83,51,106,24$, and 108 cells in mice $1-7$, respectively). Sample size for this experiment was chosen to allow robust statistical analysis of data, including multivariate analyses, in a manner comparable to the other few in vivo taste cell imaging studies published (Chen et al., 2011; Barretto et al., 2015; Wu et al., 2015). For anatomical studies, we used 7 adult C57BL/6J (4 female, 3 male) mice with anterograde tracer injections made in the VPMpc. A subset of these mice ( 2 female, 1 male) were also stimulated intraorally with quinine to examine taste-evoked c-Fos expression in GC. Slidemounted brain sections spanning the rostral-caudal extent of GC and VPMpc in all mice were examined via fluorescent and/or confocal microscopy; representative examples of labeling were acquired from some sections. These data were not analyzed in a quantitative manner. Sample sizes were chosen to approximate those used in our previous studies of brainstem anatomy and taste-evoked Fos expression (Tokita et al., 2009, 2014; Savchenko et al., 2011). Eight C57BL/6J mice (all male) were used for the licking behavior test (one was removed during the test for failure to lick water during the training sessions, leaving a final $n=7$ ). This experiment was conducted to test whether the taste stimuli used for imaging would provoke an aversive, neutral, or appetitive response relative to water; therefore, all mice were tested in the same way on the same days with the same stimuli. Sample size was based on our earlier licking behavior studies (Boughter et al., 2005; Saites et al., 2015).

Analysis of imaging data was performed in R Studio software (version 0.98.1103; RRID:SCR_001905). All raw fluorescence traces were compiled and interpolated to the fastest frame rate $(t=0.309 \mathrm{~s})$ using the spline function. Traces were smoothed using a three-frame rolling mean function. To quantify taste-specific responses, the taste-evoked change in fluorescence $(\Delta F)$ from each trace was calculated by subtracting the $8 \mathrm{~s}$ frame average during the pretaste water presentation from a 5 -frame average centered on the peak of the response generated during the taste presentation. The relative change in fluorescence $(\Delta F / F)$ was then calculated by dividing the taste-evoked change in fluorescence by the mean fluorescence. Responsive cells were defined as having a $\Delta F / F$ greater than that of the mean $\pm 2.5 \mathrm{SD}$ of the pretaste water presentation for each trial.

Entropy, a measure of breadth of tuning, was calculated for each neuron (Smith et al., 1979) as follows:

$$
H=-K\left(\sum_{i=1}^{4} P i \log P i\right)
$$

where $P i$ represents the response to each of the four taste stimuli and $K$ is a scaling constant (1.661 for four stimuli). Values of entropy $(H)$ close to zero indicate response to only a single stimulus (narrow tuning) and values close to 1.0 indicate response to all four stimuli (broad tuning). We also calculated an additional measure of response breadth: the noiseto-signal (N/S) ratio (Spector and Travers, 2005). This ratio is derived by dividing the response to the second-best stimulus (the maximum noise elicited by sideband stimuli) by the response to the best stimulus (signal). Similar to $H$, this measure also ranges from 0.0 to 1.0 .

For cluster analysis, all taste responses for each cell were normalized to the maximum taste-evoked response for that cell. Responsive cells from all mice were combined and hierarchical cluster analysis and principle components analysis were performed using JMP software (RRID:SCR_014242); the outcomes of these analyses are shown in the Results. Mean normalized distances between cells (according to best taste, cluster, and tuning) were calculated by dividing the distance between each cell of a particular category by the mean of the distance between all the cells in the imaging window. We then used the Wilcoxon signed-rank test to examine potential significant deviations from a theoretical median of 1.0 (see Results). Narrow and broad cells were also directly compared with respect to distances using a Mann-Whitney $U$ test (see Results).

For analysis of licking behavior, data were averaged across the $2 \mathrm{~d}$ of testing for each mouse and mean lick ratios (average licks to stimulus/ average licks to water) for each stimulus were calculated. Statistical analysis was performed using GraphPad Prism software (RRID:SCR_002798). Oneway ANOVA was used to test whether there was an overall difference among stimuli and one-sample $t$ tests were used to evaluate whether lick ratios to a particular stimulus differed significantly from water (value $=1.0$ ). The outcomes of these tests are provided in the Results.

\section{Results}

We used 2P imaging of the virally expressed calcium reporter GCaMP6s to study taste quality representation within GC neurons in cortical layers II/III, testing whether they possess specific responses and if they tend to group together in space across the GC surface. We first verified the extent of GC in mice by making injections of the anterograde tracer MicroRuby into the VPMpc (Fig. 1). In all mice ( $n=7)$, VPMpc injections consistently labeled thalamic fibers that ramified throughout all cortical layers of predominantly dysgranular insular cortex, but also to some extent in granular and agranular cortex, ranging from $\sim 1.5 \mathrm{~mm}$ anterior to bregma to $-0.5 \mathrm{~mm}$ posterior to bregma (Fig. $1 E, F$ ). This location is consistent with anatomical and physiological studies in the rat showing that the GC is located in dysgranular/ agranular insular cortex, although there is evidence that granular cortex may function as part of GC as well (Kosar et al., 1986a, 1986b; Cechetto and Saper, 1987; Yamamoto et al., 1989; Allen et al., 1991; Ogawa et al., 1992; Nakashima et al., 2000). However, the possibility cannot be ruled out (due to injection site spread) that some of the labeling represents nongustatory input. We also found QHCl-evoked Fos expression overlapping with labeled thalamic fibers, further demonstrating the labeled area is responsive to taste (Fig. $1 G$ ). These results agree with a previous study in the rat, in which quinine-evoked Fos was found in dysgranular and agranular cortex throughout the rostral-caudal extent of $\mathrm{GC}$, with the greatest expression in the center of this axis (King et al., 2014).

Because previous imaging studies focused on an anatomically defined region of GC delineated by the MCA and bifurcation of the caudal rhinal veins (Accolla et al., 2007; Chen et al., 2011), we targeted our viral injections to this region (Fig. $2 A, B, D$ ). $2 \mathrm{P}$ imaging in these mice revealed large populations of labeled cells within layer II/III of our imaging window. In a subset of these mice $(n=2)$, we also injected AAV1.CB7.CI.mCherry into VPMpc to label thalamic fibers in GC. As can be seen in Figure $2 C$, we found dense overlap between thalamic fibers (red) and GCaMP-labeled GC cells (green), verifying that the imaging region is located within GC.

In seven mice, we recorded significant taste-evoked activity in $88 \%$ of examined neurons ( 783 of 891 cells in 24 microscope fields). For each field, responses were recorded from all visible cells, allowing us to generate a taste stimulus profile and spatial location for each cell. Individual cell taste responses were repeatable across stimulus presentations (Fig. $3 A$ ) and the overall percentage of responding cells did not change as stricter response criteria were applied (see Materials and Methods; Fig. 3B). Both example traces and population data show a large number of cells responding selectively to a single taste stimulus, as well as individual cells responding to two or more taste stimuli (Fig. 3C-E). Significant taste responses in individual cells ranged from $9.8 \%$ to $492.0 \% \Delta F / F$ (mean response: $32.9 \pm 0.8 \% \Delta F / F$ ). The percentage of cells with best responses to each tastant was similar (C: 29\%, N: 19\%, Q: 25\%, S: 26\%; Fig. 3F). The percentage of cells responding to each tastant (C: 60\%, N: 54\%, Q: 51\%, S: 49\%; Fig. $3 G$ ) and the overall mean responses to each tastant (C: $30.3 \pm$ 

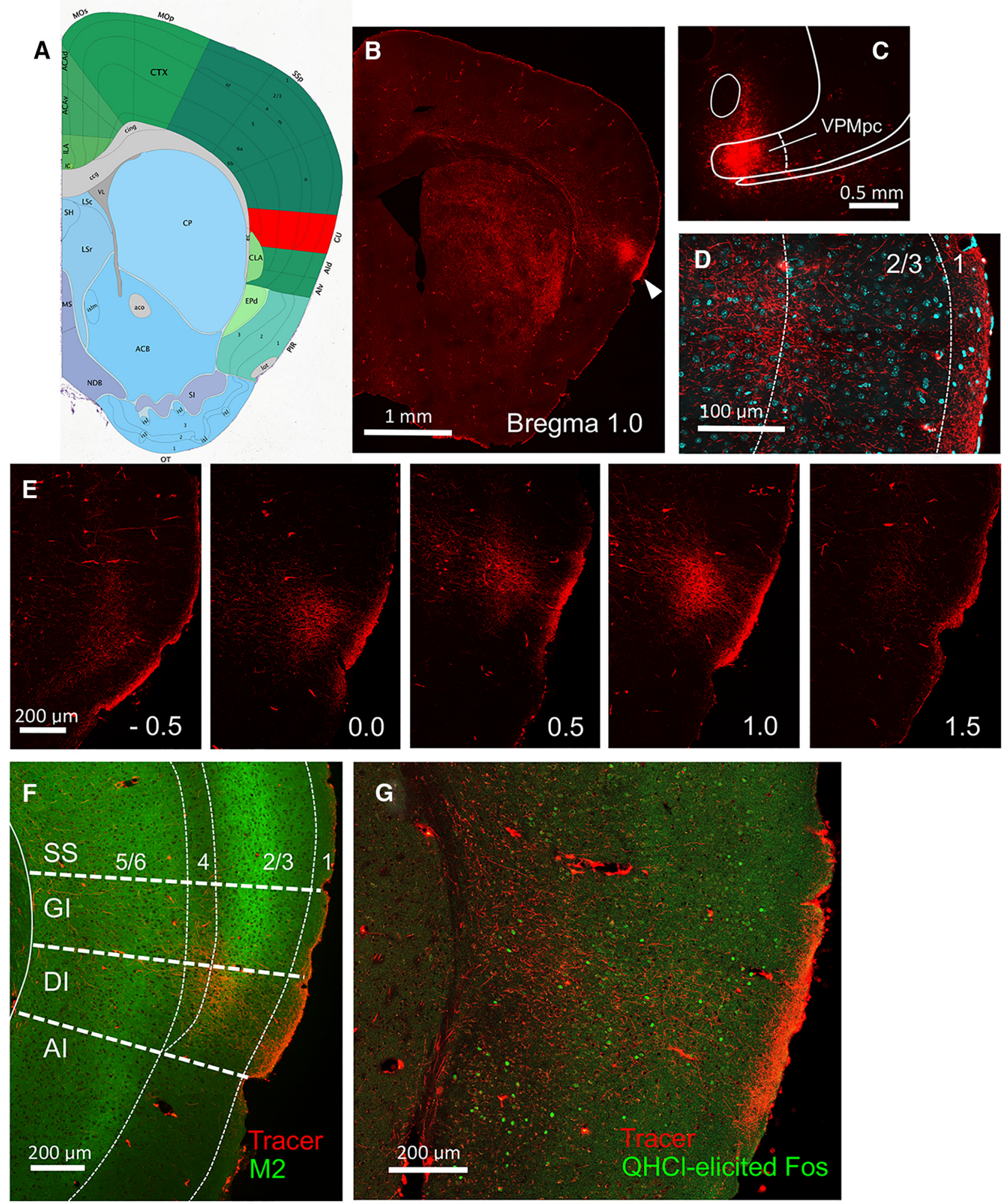

Figure 1. Delineation of GC with neural tracing and immunocytochemistry. Image 45 from the ABA P56 Coronal Reference Atlas at $0.95 \mathrm{~mm}$ anterior to bregma is shown in $A$, with $\mathrm{GC}$ colored in red. An anterograde tracer (MicroRuby) was injected unilaterally into the gustatory thalamus (VPMpc) of several B6 mice; terminal labeling was subsequently examined in GC. $\boldsymbol{B}$, Whole-brain section showing terminal labeling concentrated in the ipsilateral cerebral hemisphere in a lateral position (arrowhead) and at an anteroposterior level approximately equivalent to the ABA schematic. C, Tracer injection site in VPMpc. D, Magnified view of terminal labeling (red) interposed with cellular stain (DAPI; cyan) shows diffuse thalamic input with concentrations in cortical layers 1, 3, and 4. $\boldsymbol{E}$, Sequential sections from the same mouse show terminal labeling from caudal to rostral levels, from -0.5 to $1.5 \mathrm{~mm}$ anterior to bregma; labeling was most robust from $\sim 0.0$ to $\sim 1.2 \mathrm{~mm}$. $\boldsymbol{F}$, Muscarinic M2-type receptor (green) is concentrated in layers 3 and 5 of 6 -layer neocortex; the expression in layer 2 dissipates ventrally as the granular insular cortex (GI) gives way to the dysgranular insular cortex (DI), which is cytoarchitecturally characterized by the gradual disappearance of layer 4 (the granular layer). Thalamic expression in this section (red) is largely located in the DI. G, Taste-evoked Fos expression ( $0.003 \mathrm{~m}$ QHCI delivered IO to an awake mouse) also overlaps with the thalamic terminal field in $\mathrm{GC}$. Photographs in $\boldsymbol{B}$, $\boldsymbol{C}$, and $\boldsymbol{E}$ are all from the same mouse; those in $\boldsymbol{D}$ and $\boldsymbol{F}$ are from another mouse and $\boldsymbol{G}$ is from another. All boundaries superimposed on images are approximate. SS, Somatosensory cortex; Al, agranular insular cortex. 
A

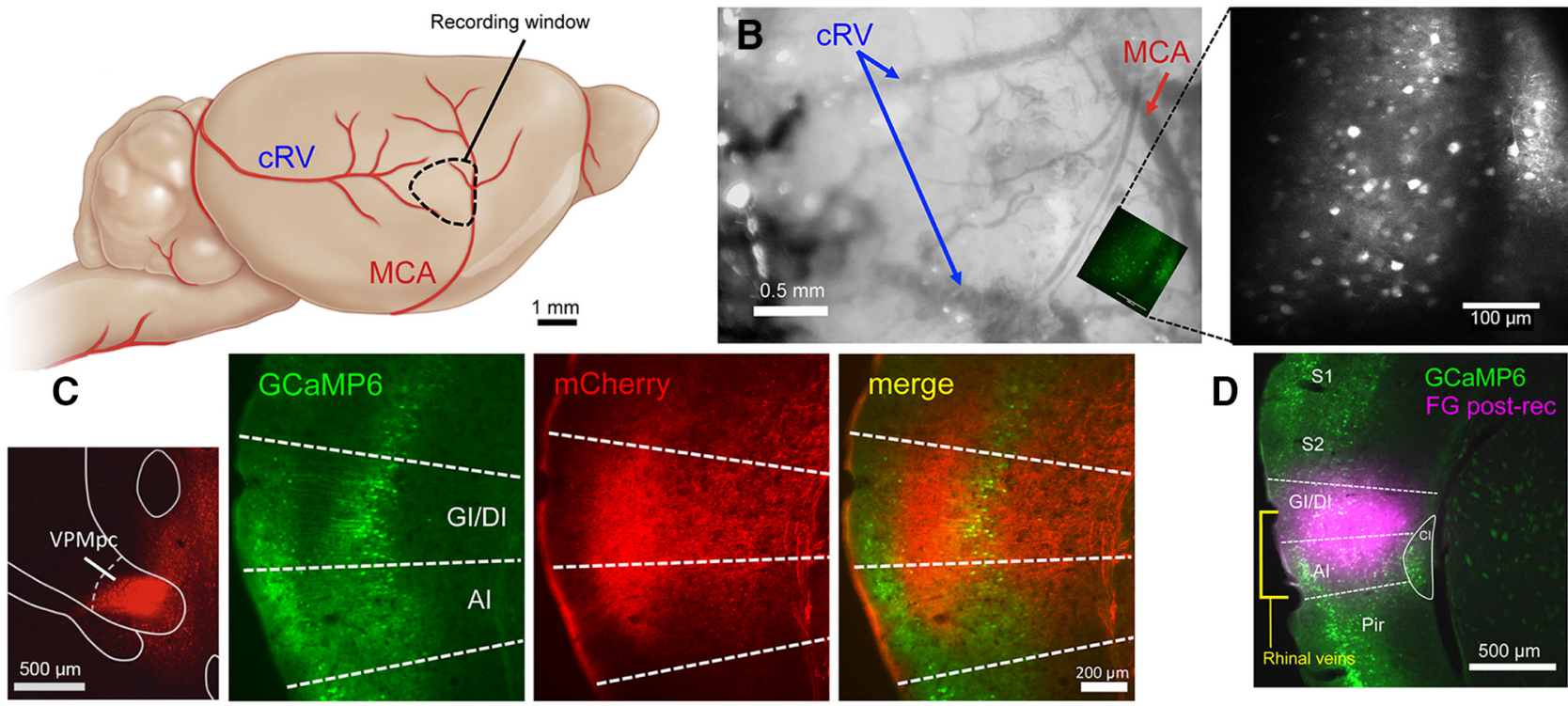

Figure 2. Location of recording fields for $2 \mathrm{P}$ imaging. $\boldsymbol{A}$, Diagram depicting region of recordings based on vasculature. $\boldsymbol{B}$, Example image taken from a recording window with one imaging field superimposed. Right, Two-photon image of example field showing labeled neurons. C, GCaMP-visualized neurons were verified to be within GC by the presence of anterograde mCherry-labeled VPMpc thalamic fibers. D, Example of postimaging location verification. Fluorogold (FG) was injected into the recording field to show that recordings were from GC neurons. CRV, Caudal rhinal vein; GI/DI, granular/dysgranular insular cortex; Al, agranular insular cortex; S1, primary somatosensory cortex; S2, secondary somatosensory cortex; Pir, piriform cortex. Schematic in $A$ is modified from Hagen et al. (2012).

1.3\%, N: $33.7 \pm 1.7 \%$, Q: $28.6 \pm 1.4 \%$, S: $39.0 \pm 2.2 \%$; Fig. $3 H$ ) were similar, with substantial overlap in this region.

To investigate population coding, we pooled all responsive cells from all mice and performed multivariate analysis of normalized taste responses. Hierarchical cluster analysis of the responses identified nine distinct neural taste profiles (Fig. 4A, B). Importantly, cells representing each cluster could be found in all mice. For each cluster, we calculated the mean entropy (Fig. 4C, Table 1) and mean N/S value (Fig. 4D, Table 1). Based on this, the cell clusters comprised two taste quality groups, with four singly tuned clusters representing each individual tastant and five broadly tuned clusters responding to different combinations of tastants. Using this classification, we found a majority $(65 \%)$ of cells to be narrowly tuned rather than broadly tuned (Fig. 4E).

Principal components analysis demonstrated robust separation of primary taste qualities along the first three components axes (Fig. 5A). Moreover, taste stimuli were ordered along the first component in a way that may reflect hedonic character, with the greatest separation found between the two aversive stimuli (citric acid and quinine) and the appetitive taste stimulus (sucrose). Using the same concentrations, we measured licking behavior to these stimuli in thirsty mice (Fig. $5 B$ ); mean lick ratios relative to water differed significantly according to each taste quality (S: $1.34 \pm 0.10, \mathrm{~N}: 0.99 \pm 0.17, \mathrm{C}: 0.46 \pm 0.07, \mathrm{Q}: 0.20 \pm$ 0.03 ; one-way ANOVA, $F_{(3,24)}=23.2, p=0.0000003$; Fig. $\left.5 B\right)$. One-sample $t$ tests revealed that mice preferred sucrose $\left(t_{(6)}=\right.$ $3.14, p=0.02)$ and avoided citric acid $\left(t_{(6)}=7.82, p=0.0002\right)$ and quinine $\left(t_{(6)}=23.56, p=0.000004\right)$ while displaying no preference for $\mathrm{NaCl}\left(t_{(6)}=0.04, p=0.97\right)$.

Finally, to investigate the spatial distribution of cells along the surface of GC based on quality response and tuning, we determined the location of each cell within each imaging field. Response maps were constructed on a Cartesian grid (Fig. 6), with each cell labeled by best taste, response cluster, or tuning breadth (broad or narrow). Across all imaging windows, no obvious grouping of cells was seen based on any of these classifications.
When mapped by best taste (Fig. 6A), the normalized pairwise distances between cells was not significantly different than one (Wilcoxon signed-rank test, theoretical median of $1.0 ; p>0.05$ for each group; mean values: S-best $=0.97 \pm 0.18, p=0.303$; $\mathrm{N}$-best $=0.93 \pm 0.23, p=0.381 ; \mathrm{C}$-best $=0.93 \pm 0.21, p=0.094$; Q-best $=1.05 \pm 0.25, p=0.776)$. Further, for each cluster, the normalized pairwise distances between cells was also not significantly different from 1 (Wilcoxon signed-rank test, theoretical median of 1), suggesting that cells belonging to individual clusters do not tend to be spatially grouped within a given field (mean values: cluster $1=0.99 \pm 0.09, p=0.855$; cluster $2=0.76 \pm 0.10$, $p=0.055$; cluster $3=0.92 \pm 0.05, p=0.240$; cluster $4=0.95 \pm$ $0.10, p=0.844$; cluster $5=0.97 \pm 0.13, p=0.846$; cluster $6=$ $1.01 \pm 0.09, p=0.600$; cluster $7=0.85 \pm 0.09, p=0.219$; cluster $8=1.07 \pm 0.07, p=0.390$; cluster $9=0.79 \pm 0.10, p=0.098$; Fig. $6 B)$. However, when cells were grouped according to entropy (Fig. 6C), the distance between broadly tuned cells was significantly less than the mean distance between all cells (Wilcoxon signed-rank test, theoretical median of 1 ; mean values: narrow $=$ $1.01 \pm 0.04, p=0.688$; broad $=0.87 \pm 0.05, p=0.014$ ) and were found to be closer together on average than narrowly tuned cells (Mann-Whitney test, $p=0.009$; Fig. $6 F$ ), suggesting some slight clustering of broadly tuned cells within GC.

\section{Discussion}

\section{Coding of taste quality in cortical neurons}

Cortical taste neurons varied in their responses to stimuli representing the four basic tastes. Neurons were found that responded to just one of the four primary taste stimuli, while other neurons were more broadly tuned, responding to two, three, or even all four stimuli. Nearly all gustatory physiology studies published over the last half-century have reported the existence of both "specialist" and "generalist" taste-responsive cells, from peripheral sensory neurons to the cortex, in studies with either anesthetized or awake and behaving animals (Spector and Travers, 2005; 
A
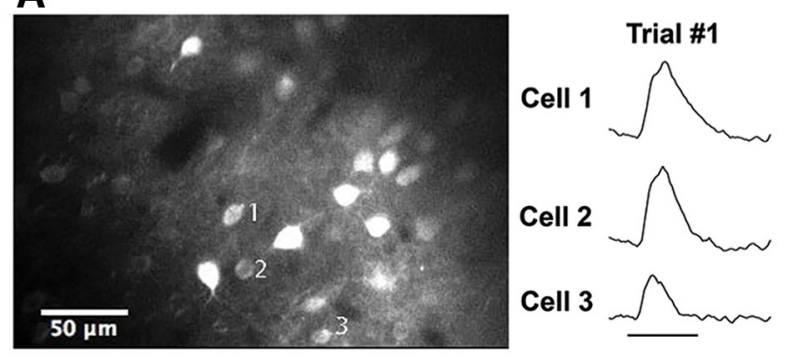
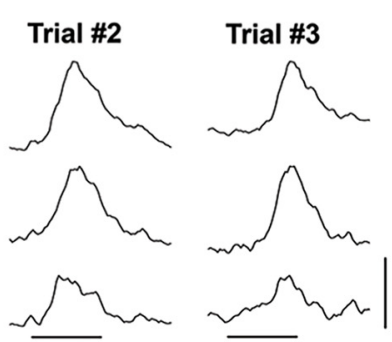

B

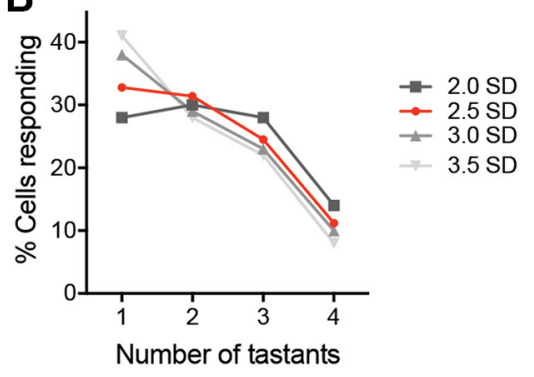

C Sucrose $\quad \mathrm{NaCl}$ Citric Acid $\quad$ Quinine
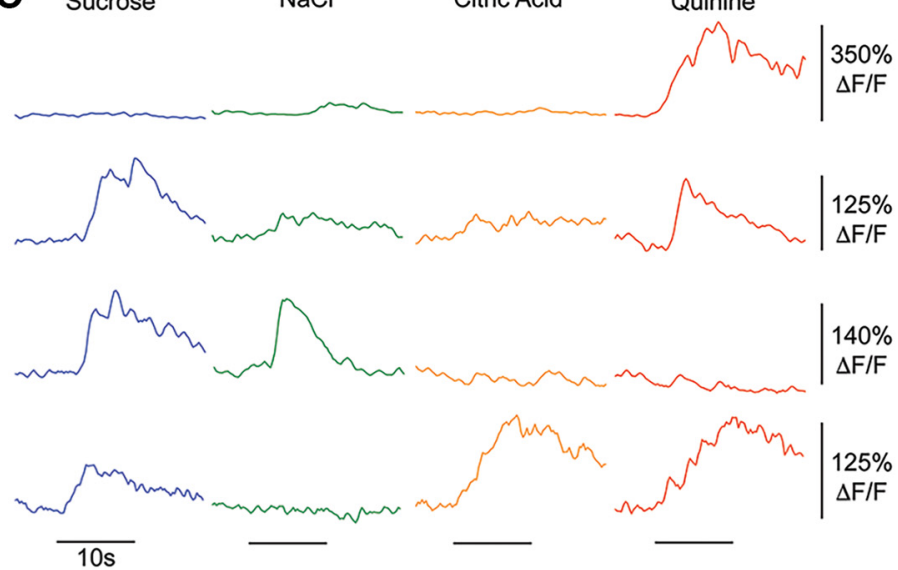

D
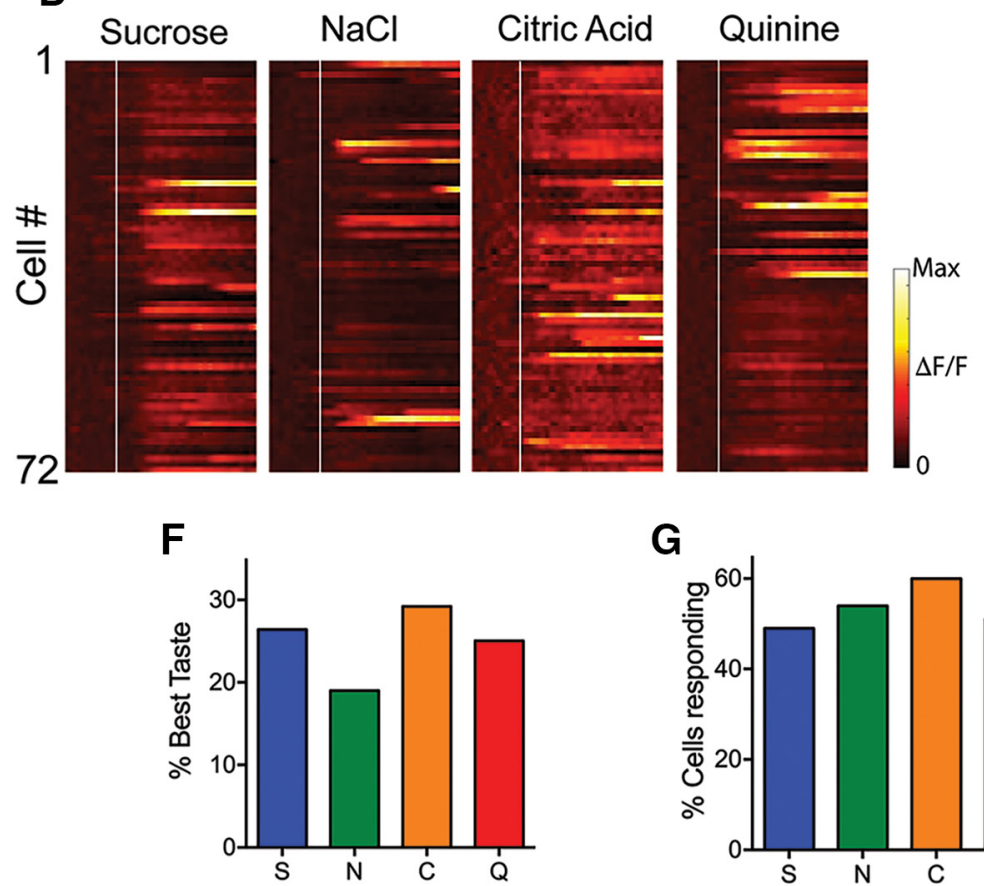

G

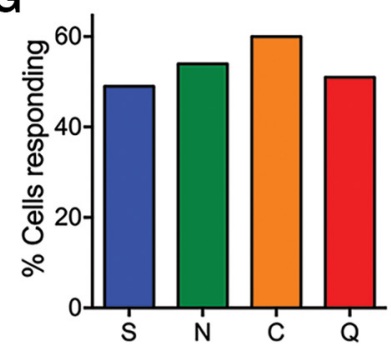

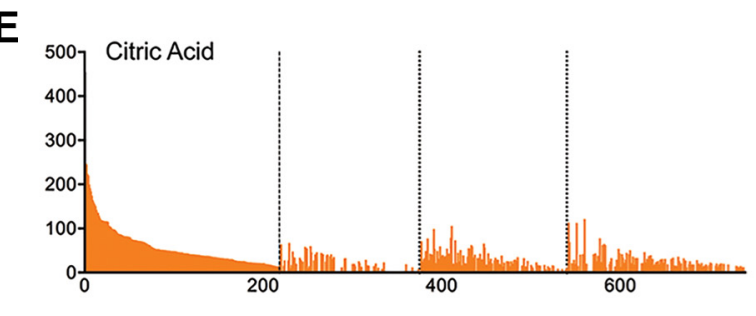
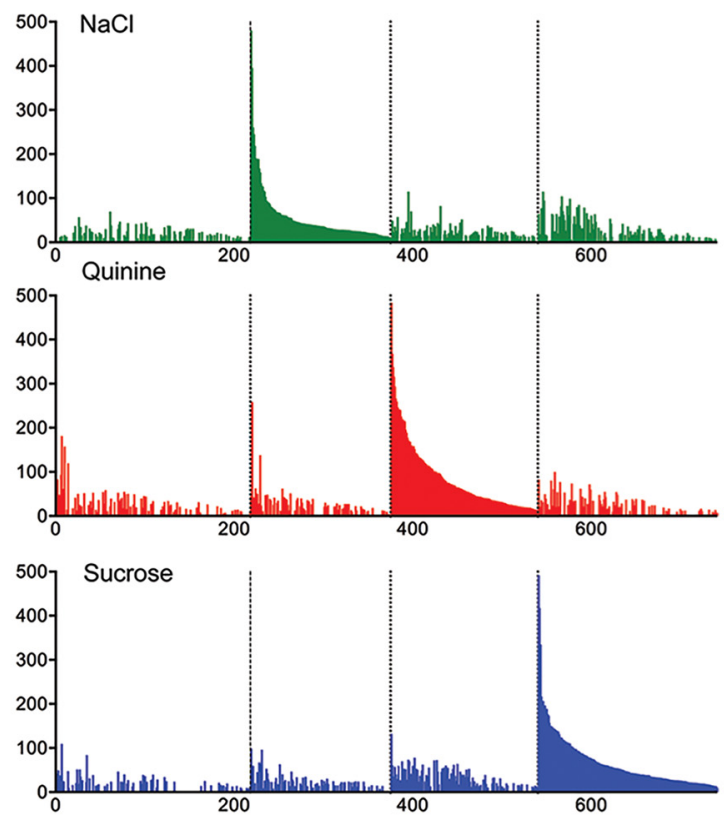

H

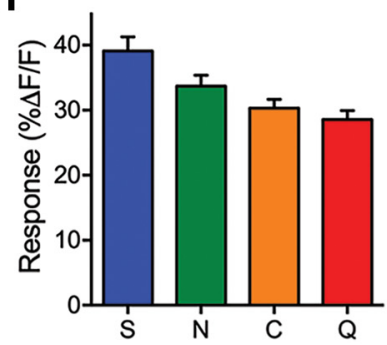

Figure 3. A, Taste-evoked imaging responses in layer II/III GC neurons. Fluorescence traces show that multiple taste presentations separated by several minutes evoke similar responses from the three labeled neurons. Horizontal scale bar, $5 \mathrm{~s}$; vertical scale bar, $200 \% \Delta F / F$. B, Individual cell response thresholds were set at 2.0, 2.5, 3.0, and 3.5 SDs and the percentage of cells responding to only one, two, three, or four tastants were compared. All other thresholds (grays) produced highly similar percentages of cells as the 2.5 (red) chosen for analysis. C, Example traces from four different GC neurons to taste application (black bar). D, Normalized taste-evoked responses from all cells taken from the field shown in Figure $2 B$. White line depicts onset of taste delivery. Each row in the "heat map" represents a cell and time is represented along the $X$-axis. Individual neuron responses vary in their selectivity and temporal response. $\boldsymbol{E}$, All responsive neurons grouped into best-stimulus categories (colors) and arranged in descending order of response magnitude to that stimulus. $\boldsymbol{F}$, Percentage of cells by best taste stimulus. $\mathbf{G}$, Similar percentages of cells significantly responding to each taste. $\boldsymbol{H}$, Mean fluorescence change evoked by each taste across the cell population.

Simon et al., 2006; Carleton et al., 2010). Using hierarchical cluster analysis, we identified approximately comparable numbers of narrowly tuned taste neurons, or specialists, for each of the basic taste stimuli. Collectively, specialists accounted for $64 \%$ of all taste-responsive cells. Interestingly, this ratio resembles that found for geniculate ganglion taste neurons in two recent imaging studies (Barretto et al., 2015; Wu et al., 2015). Overall neuronal selectivity can also be inferred by breadth-of-tuning measures 


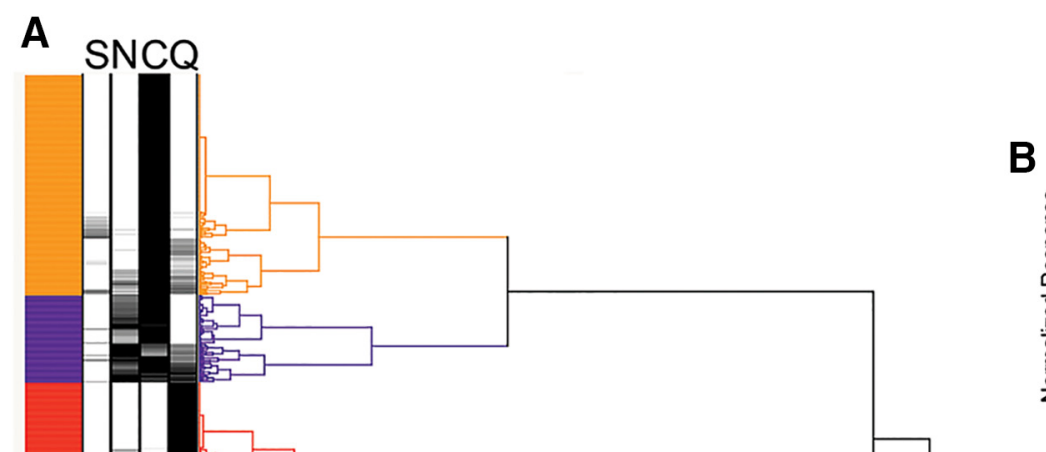

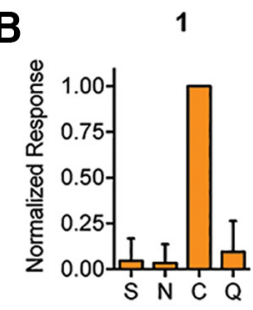
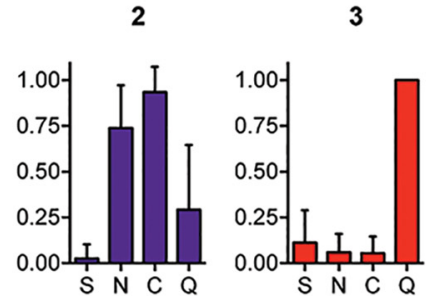

4
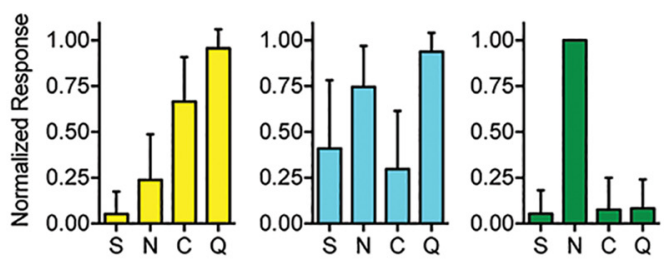

7

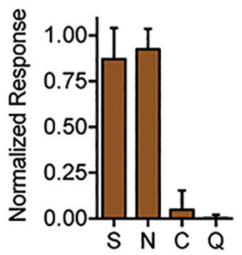

8
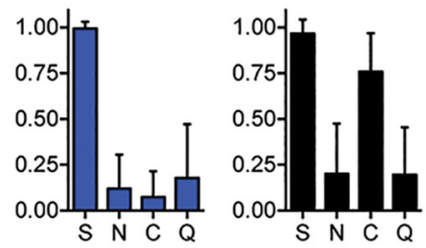

0

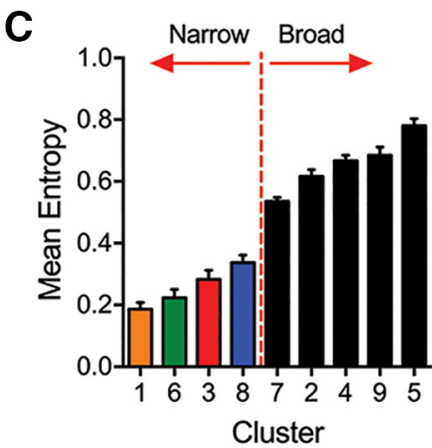

D

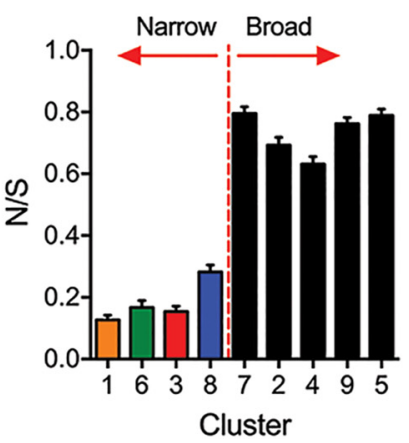

E

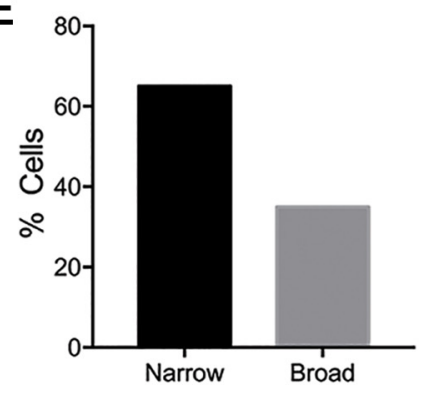

Figure 4. Clustering and breadth of responsiveness among all neurons. $A$, Hierarchical cluster analysis reveals groups of cells with distinct taste response profiles. $\boldsymbol{B}$, Normalized taste response profiles (mean \pm SD) for each cluster in $\boldsymbol{A}$ revealing both singly tuned and more broadly tuned cell types. Entropy $(\boldsymbol{C})$ and $N / S(D)$ analysis demonstrate narrowly and broadly tuned cell clusters. E, Percentage of strongest (top 10\% by maximum response) responding cells according to cluster.

such as entropy or N/S ratio; in these experiments, overall mean entropy was $0.40 \pm 0.01$ and the N/S ratio was $0.38 \pm 0.01$ (SEM); both of these values support a preponderance of narrowly tuned cells in GC. Studies of taste brainstem physiology in C57BL/6J mice reveal a greater degree of broad tuning: Higher entropy (0.73) for the nucleus of the solitary tract and higher entropy (0.64) and N/S (0.43) values for the parabrachial nucleus (Lemon and Margolskee, 2009; Tokita and Boughter, 2016). There does not appear to be greater convergence of taste quality information into individual cells in the cortex versus lower areas. However, it is important to consider that breadth of tuning may be affected by anesthesia state or method of data thresholding. Evidence for sharpening of taste profiles in GC in rat studies is equivocal (Spector and Travers, 2005).

What then, are the functional implications of specialist and generalist taste cell types in mouse GC? There is some evidence, albeit limited, that variation in breadth of tuning could reflect different cell types; that is, pyramidal cells versus interneurons (Yokota et al., 2011). Tuning profiles may also correlate with cortical depth or projection. Projection cells, located in GC in rats in greatest abundance in layer $\mathrm{V}$, target other parts of cortex, including ipsilateral GC and orbitofrontal cortex, as well as subcortical structures such as thalamus, amygdala, and brainstem (Allen et al., 1991; Fujita et al., 2012; Maffei et al., 2012). Our imaging responses were collected within layer II/III. There was evidence for spatial clustering of broadly tuned neurons (although it was a small effect), but not taste quality per se in our data, possibly indicating a shared function of such cells. Interestingly, our data adhered well to the specific-to-general cellassembly model recently described by Xie et al. (2016) for other cortical areas. In this model, distinct stimuli activate pyramidal 

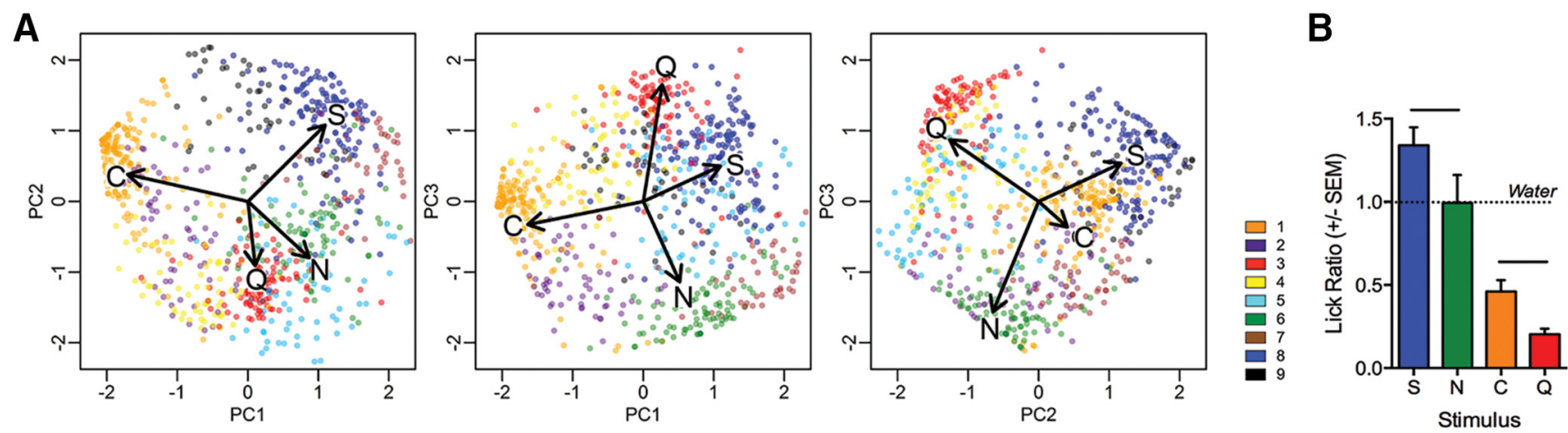

Figure 5. Principle components analysis. A, Two-dimensional plots of the first three principal components (accounting for $91 \%$ of the total variance) relative to one another reveal that the population data effectively and separately encodes each tastant in coding space. In all graphs, the individual cell positions are plotted and color coded according to cluster to demonstrate how each cluster contributes to the coding of each taste stimulus. $\boldsymbol{B}$, Mean lick ratios relative to water differ according to each taste quality. Overall, water-restricted mice preferred sucrose and avoided citric acid and quinine while displaying no preference for $\mathrm{NaCl}$ compared with water. Asterisks above bars indicate significantly different groups. Error bars indicate SEM.

cells according to power-of-two permutation based logic, such that neural networks are organized to respond to relevant and possibly all combinations of stimuli, including specialists and generalists. Specific responding cells are predicted to be overrepresented in superficial cortical layers, as was found in our study.

The diverse connection pattern apparent in combinations of neuronal responder types offers increased computational power and flexibility (Xie et al., 2016), which are ideal features for GC, where stimulus processing is linked to attentional states and taste-based leaning (Fontanini and Katz, 2008; Samuelsen et al., 2012; Schier et al., 2016). Awake multielectrode recordings in rats indicate that information reflecting multiple facets of taste, including quality and hedonic valence, may be encoded in the temporal activity of ensembles of cortical cells (Katz et al., 2001; Jezzini et al., 2013). Although we did not record from behaving mice or analyze temporal patterns of response (making direct comparison to the aforementioned studies difficult), principle components analysis of our data supported the premise that, in addition to quality, information about hedonic character might also be reflected in the activity patterns of all cell types. This is driven by the degree of convergence of aversive, appetitive, or neutral stimuli in broadly tuned cells (also see Yamamoto et al., 1989; Nishijo et al., 1998; Fig. 4). However, there are several important caveats to this conclusion. We attempted to verify the hedonic value of our stimuli using a brief-access taste behavioral assay. Although these tests are useful in limiting effects of postingestive and other nontaste factors, the mice were fluid restricted, limiting the response differential relative to water (which they will lick at a high rate due to thirst). Although there is little doubt as to whether C57BL/6J mice prefer sucrose and avoid quinine or acid (Bachmanov et al., 1996; Boughter et al., 2005), this limitation is crucial for $\mathrm{NaCl}$, which varies in hedonic value according to concentration (Bachmanov et al., 1996; Oka et al., 2013). Second, a larger stimulus panel would allow for more detailed analysis of potential similarities in response among groups of appetitive or aversive stimuli, including additional compounds in the same stimulus class, as well as concentrations of individual stimuli that vary in hedonic value.

\section{Topography of taste quality in GC}

The issue of whether there is a spatial map of taste quality within particular brain areas has received a fair amount of study, even in human taste GC (Singh et al., 2011). GC comprises a subregion of so-called insular cortex and (in rodents) is located on the lateral ventral surface of the brain. Its spatial and functional character- istics have been much better defined in rats than mice. According to the ABA, mouse GC extends for $\sim 2.4 \mathrm{~mm}$ along the AP axis, corresponding to about +2.0 to -0.4 from bregma. We imaged taste cell responses just caudal to the MCA, which we estimate lies on the external brain surface at $\sim+1.0 \mathrm{~mm}$ from bregma (Hashimoto and Spector, 2014; Kida et al., 2015; although, in rats, the location of MCA with respect to actual brain landmarks has been shown to be variable). Abundant input from the VPMpc was found in this region, in a dorsal-ventral location similar to the designation of GC in ABA and corresponding primarily to the dysgranular insular cortex (characterized by the attenuation of layer 4).

Our imaging responses provide compelling evidence in mice that the rostral-caudal "center" of GC contains overlapping representations of taste quality, challenging notions of labeled-line coding via segregated, quality-specific cell "hotspots." In particular, we recorded robust and reliable responses to four basic stimuli in a region that a previous imaging study found to be essentially devoid of taste-evoked activity (Chen et al., 2011). Overlap among responses to basic taste qualities in the center region is similar to results gained using other approaches in anesthetized rats, including wide-field optical imaging (Accolla et al., 2007; Accolla and Carleton, 2008) and single unit in vivo recordings (Yamamoto et al., 1985b). Moreover, this area is targeted in most awake recording studies, linking taste responses to behavioral function (Katz et al., 2001; Fontanini and Katz, 2008; Samuelsen et al., 2012; Maier and Katz, 2013). Lesions centered in this area have effects on salt discrimination $(\mathrm{NaCl}$ vs $\mathrm{KCl})$ and on quinine and $\mathrm{KCl}$ operant-based gustatory detection, although not on hedonic (unconditioned) responses to either quinine or sucrose (Hashimoto and Spector, 2014; Bales et al., 2015; Blonde et al., 2015; King et al., 2015). Finally, taste-nerve-dependent quinine-induced Fos expression is found across the anteriorposterior axis of GC and is actually strongest in the center region (King et al., 2014).

The tension between our results and the Chen et al. (2011) study may be due to several different factors. The methodology is somewhat different because the current study used virally expressed GCaMP6s rather than a bulk-loaded AM dye, allowing for greater penetration into cortical layers II/III. GCaMP6s is a more sensitive indicator (Chen et al., 2013) and it is possible that more subtle taste responses, including "sideband" responses, were not registered in the previous study. In addition, Chen et al. (2011) investigated areas more anterior or posterior to the region that we focused on, so it is possible that greater concentrations of 
A

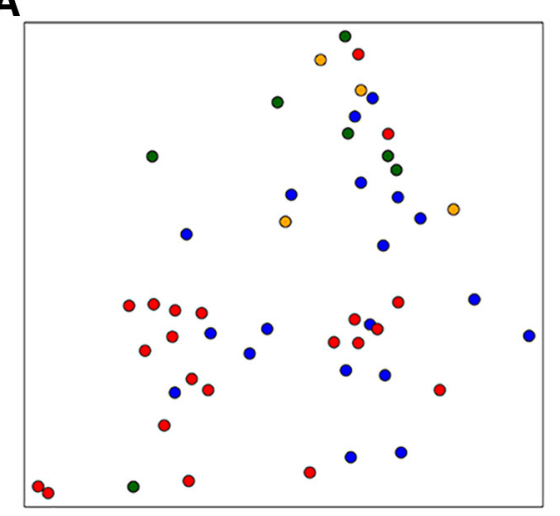

B

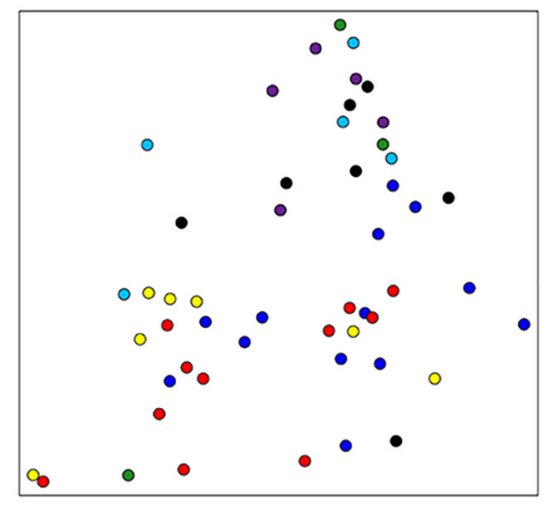

C

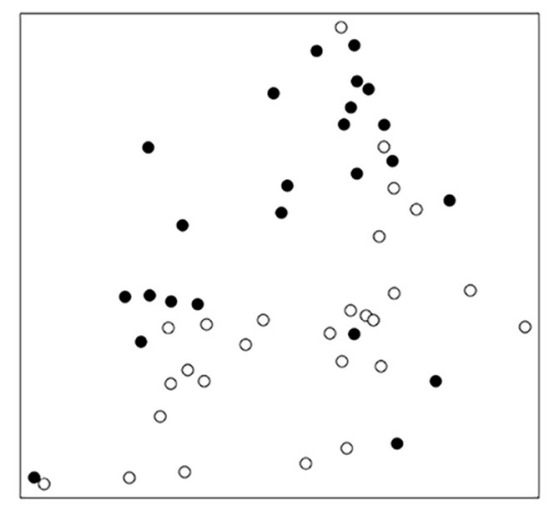

D

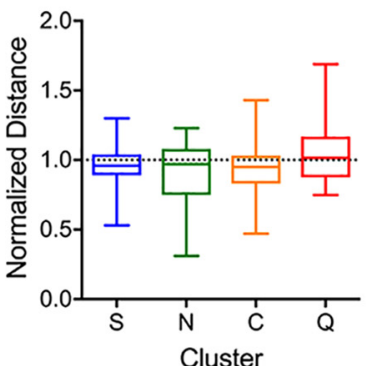

Best Taste
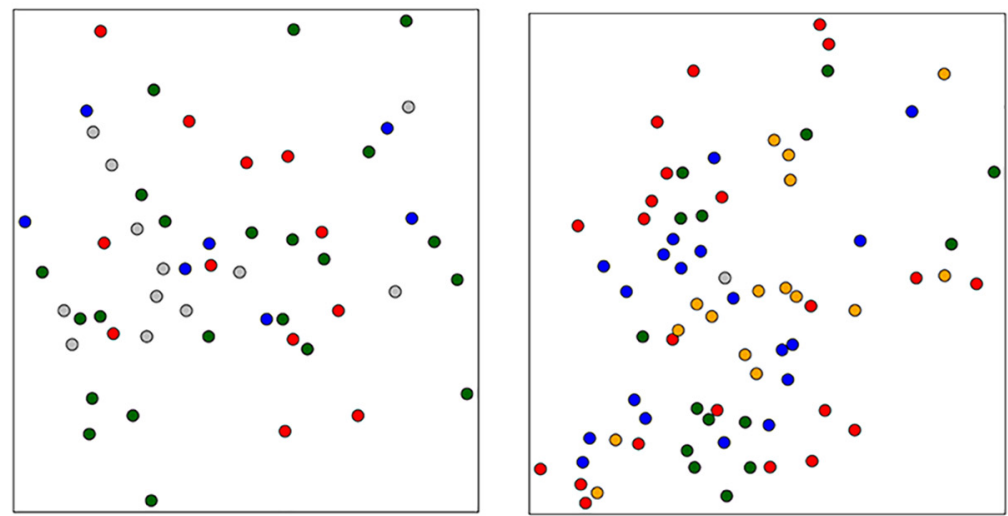

$\square \mathrm{NR}$
$\square \mathrm{C}$
$\mathrm{O}_{\mathrm{N}}$
$\mathrm{N}$

\section{Cluster}
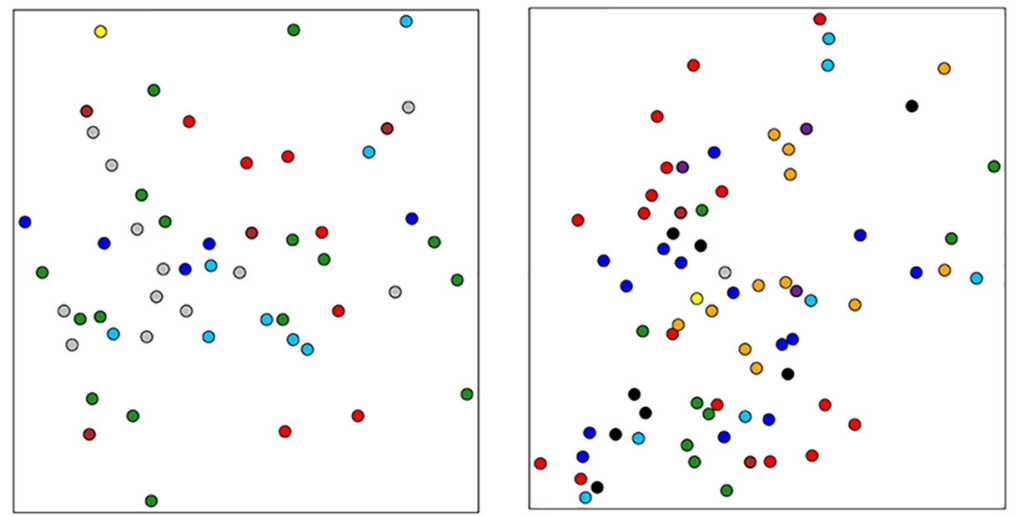

$\square$ NR
$\square 1$
$\square 3$
$\square$
$\square 5$
$\square$
6
7
8
9

\section{Entropy}
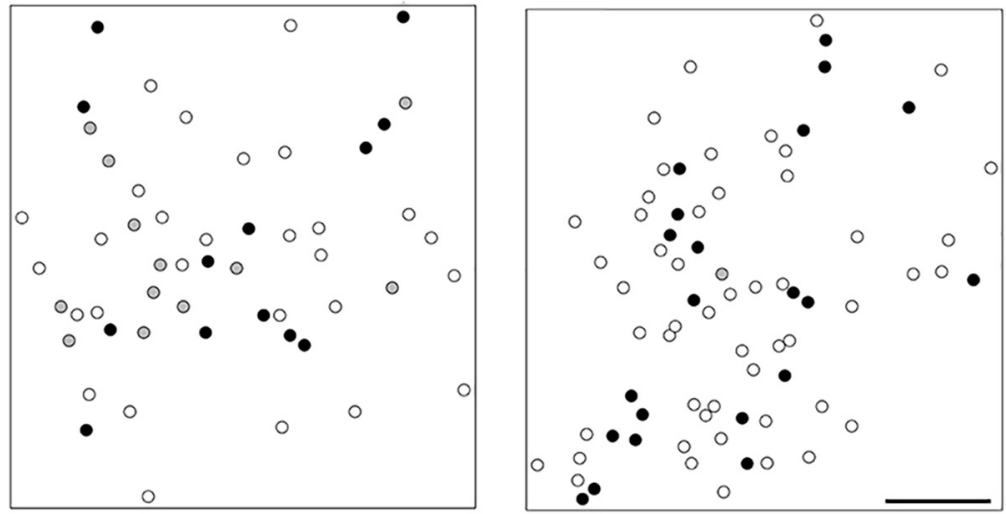
$\square$ Narrow

E

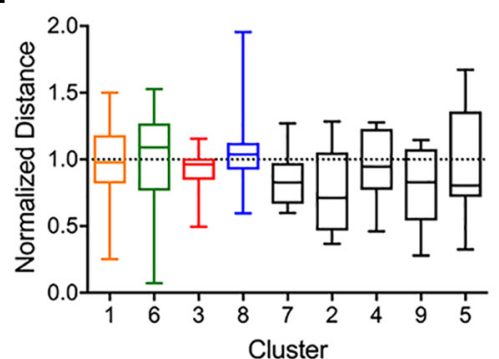

$\mathbf{F}$

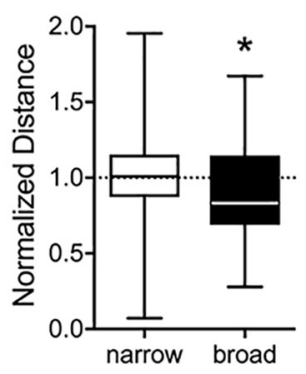

Figure 6. Spatial analyses according to taste response and entropy. Examples of the spatial distribution of neurons within individual fields of $\mathrm{GC}$ in different mice based on best taste $(\boldsymbol{A})$, cluster $(\boldsymbol{B})$, and tuning breadth for each mouse. Normalized distances between cells categorized by best taste $(\boldsymbol{D})$, cluster $(\boldsymbol{E})$, and breadth of tuning $(\boldsymbol{F})$. ${ }^{*}$ Denotes a significant difference from 1. 
particular best-stimulus cell types are found at the rostral or caudal extremes of GC, whereas there is more mixing in the center, as in the rat studies (Yamamoto et al., 1985b; Accolla et al., 2007). It must be emphasized, however, that, in these previous rat mapping studies, any such biasing at the extremes corresponded to a gradation of numbers of particular best-taste cell types rather than discrete and absolute spatial clustering (Yamamoto et al., 1985b; Accolla et al., 2007). This is similar to the way that taste qualities are organized in other central gustatory areas (Travers and Norgren, 1995; Geran and Travers, 2006; Yokota et al., 2011; Tokita and Boughter, 2016). In any case, our results point to the likelihood that significant taste responses, including to acids, are found across GC, including in between any more quality-specific regions.

\section{References}

Accolla R, Carleton A (2008) Internal body state influences topographical plasticity of sensory representations in the rat gustatory cortex. Proc Natl Acad Sci U S A 105:4010-4015. CrossRef Medline

Accolla R, Bathellier B, Petersen CC, Carleton A (2007) Differential spatial representation of taste modalities in the rat gustatory cortex. J Neurosci 27:1396-1404. CrossRef Medline

Allen GV, Saper CB, Hurley KM, Cechetto DF (1991) Organization of visceral and limbic connections in the insular cortex of the rat. J Comp Neurol 311:1-16. CrossRef Medline

Bachmanov AA, Tordoff MG, Beauchamp GK (1996) Ethanol consumption and taste preferences in C57BL/6ByJ and 129/J mice. Alcohol Clin Exp Res 20:201-206. CrossRef Medline

Bales MB, Schier LA, Blonde GD, Spector AC (2015) Extensive gustatory cortex lesions significantly impair taste sensitivity to $\mathrm{KCl}$ and quinine but not to sucrose in rats. PLoS One 10:e0143419. CrossRef Medline

Barretto RP, Gillis-Smith S, Chandrashekar J, Yarmolinsky DA, Schnitzer MJ, Ryba NJ, Zuker CS (2015) The neural representation of taste quality at the periphery. Nature 517:373-376. CrossRef Medline

Blonde GD, Bales MB, Spector AC (2015) Extensive lesions in rat insular cortex significantly disrupt taste sensitivity to $\mathrm{NaCl}$ and $\mathrm{KCl}$ and slow salt discrimination learning. PLoS One 10:e0117515. CrossRef Medline

Boughter JD Jr, Raghow S, Nelson TM, Munger SD (2005) Inbred mouse strains C57BL/6J and DBA/2J vary in sensitivity to a subset of bitter stimuli. BMC Genet 6:36. Medline

Boughter JD Jr, Baird JP, Bryant J, St John SJ, Heck D (2007) C57BL/6J and $\mathrm{DBA} / 2 \mathrm{~J}$ mice vary in lick rate and ingestive microstructure. Genes Brain Behav 6:619-627. CrossRef Medline

Braun JJ, Slick TB, Lorden JF (1972) Involvement of gustatory neocortex in the learning of taste aversions. Physiol Behav 9:637-641. CrossRef Medline

Carleton A, Accolla R, Simon SA (2010) Coding in the mammalian gustatory system. Trends Neurosci 33:326-334. CrossRef Medline

Cechetto DF, Saper CB (1987) Evidence for a viscerotopic sensory representation in the cortex and thalamus in the rat. J Comp Neurol 262:27-45. CrossRef Medline

Chen TW, Wardill TJ, Sun Y, Pulver SR, Renninger SL, Baohan A, Schreiter ER, Kerr RA, Orger MB, Jayaraman V, Looger LL, Svoboda K, Kim DS (2013) Ultrasensitive fluorescent proteins for imaging neuronal activity. Nature 499:295-300. CrossRef Medline

Chen X, Gabitto M, Peng Y, Ryba NJ, Zuker CS (2011) A gustotopic map of taste qualities in the mammalian brain. Science 333:1262-1266. CrossRef Medline

Clancy KB, Schnepel P, Rao AT, Feldman DE (2015) Structure of a single whisker representation in layer 2 of mouse somatosensory cortex. J Neurosci 35:3946-3958. CrossRef Medline

Fontanini A, Katz DB (2008) Behavioral states, network states, and sensory response variability. J Neurophysiol 100:1160-1168. CrossRef Medline

Fujita S, Kitayama T, Mizoguchi N, Oi Y, Koshikawa N, Kobayashi M (2012) Spatiotemporal profiles of transcallosal connections in rat insular cortex revealed by in vivo optical imaging. Neuroscience 206:201-211. CrossRef Medline

Geran LC, Travers SP (2006) Single neurons in the nucleus of the solitary tract respond selectively to bitter taste stimuli. J Neurophysiol 96:25132527. CrossRef Medline
Hagen CE, Bolon B, Keene CD (2012) Nervous system. In: Comparative anatomy and histology: a mouse and human atlas (Treuting PM, Dintzis SM, eds), pp 339-394. San Diego: Academic

Hashimoto K, Spector AC (2014) Extensive lesions in the gustatory cortex in the rat do not disrupt the retention of a presurgically conditioned taste aversion and do not impair unconditioned concentration-dependent licking of sucrose and quinine. Chem Senses 39:57-71. CrossRef Medline

Jezzini A, Mazzucato L, La Camera G, Fontanini A (2013) Processing of hedonic and chemosensory features of taste in medial prefrontal and insular networks. J Neurosci 33:18966-18978. CrossRef Medline

Katz DB, Simon SA, Nicolelis MA (2001) Dynamic and multimodal responses of gustatory cortical neurons in awake rats. J Neurosci 21:4478 4489. Medline

Kida I, Enmi J, Iida H, Yoshioka Y (2015) Asymmetrical intersection between the middle cerebral artery and rhinal vein suggests asymmetrical gustatory cortex location in rodent hemispheres. Neurosci Lett 589:150 152. CrossRef Medline

King CT, Garcea M, Spector AC (2014) Restoration of quinine-stimulated Fos-immunoreactive neurons in the central nucleus of the amygdala and gustatory cortex following reinnervation or cross-reinnervation of the lingual taste nerves in rats. J Comp Neurol 522:2498-2517. CrossRef Medline

King CT, Hashimoto K, Blonde GD, Spector AC (2015) Unconditioned oromotor taste reactivity elicited by sucrose and quinine is unaffected by extensive bilateral damage to the gustatory zone of the insular cortex in rats. Brain Res 1599:9-19. CrossRef Medline

Kosar E, Grill HJ, Norgren R (1986a) Gustatory cortex in the rat. I. Physiological properties and cytoarchitecture. Brain Res 379:329-341. CrossRef Medline

Kosar E, Grill HJ, Norgren R (1986b) Gustatory cortex in the rat. II. Thalamocortical projections. Brain Res 379:342-352. CrossRef Medline

Lemon CH, Margolskee RF (2009) Contribution of the T1r3 taste receptor to the response properties of central gustatory neurons. J Neurophysiol 101:2459-2471. Medline

Lin JY, Roman C, St Andre J, Reilly S (2009) Taste, olfactory and trigeminal neophobia in rats with forebrain lesions. Brain Res 1251:195-203. CrossRef Medline

Maffei A, Haley M, Fontanini A (2012) Neural processing of gustatory information in insular circuits. Curr Opin Neurobiol 22:709-716. CrossRef Medline

Maier JX, Katz DB (2013) Neural dynamics in response to binary taste mixtures. J Neurophysiol 109:2108-2117. CrossRef Medline

Nakashima M, Uemura M, Yasui K, Ozaki HS, Tabata S, Taen A (2000) An anterograde and retrograde tract-tracing study on the projections from the thalamic gustatory area in the rat: distribution of neurons projecting to the insular cortex and amygdaloid complex. Neurosci Res 36:297-309. CrossRef Medline

Nishijo H, Uwano T, Tamura R, Ono T (1998) Gustatory and multimodal neuronal responses in the amygdala during licking and discrimination of sensory stimuli in awake rats. J Neurophysiol 79:21-36. Medline

Norgren R, Wolf G (1975) Projections of thalamic gustatory and lingual areas in the rat. Brain Res 92:123-129. CrossRef Medline

Ogawa H, Hasegawa K, Murayama N (1992) Difference in taste quality coding between two cortical taste areas, granular and dysgranular insular areas, in rats. Exp Brain Res 91:415-424. Medline

Oka Y, Butnaru M, von Buchholtz L, Ryba NJ, Zuker CS (2013) High salt recruits aversive taste pathways. Nature 494:472-475. CrossRef Medline

Saites LN, Goldsmith Z, Densky J, Guedes VA, Boughter JD Jr (2015) Mice perceive synergistic umami mixtures as tasting sweet. Chem Senses 40: 295-303. CrossRef Medline

Samuelsen CL, Gardner MP, Fontanini A (2012) Effects of cue-triggered expectation on cortical processing of taste. Neuron 74:410-422. CrossRef Medline

Savchenko VL, Boughter JD Jr (2011) Regulation of neuronal activation by Alpha2A adrenergic receptor agonist. Neurotox Res 20:226-239. CrossRef Medline

Schier LA, Hashimoto K, Bales MB, Blonde GD, Spector AC (2014) Highresolution lesion-mapping strategy links a hot spot in rat insular cortex with impaired expression of taste aversion learning. Proc Natl Acad Sci U S A 111:1162-1167. CrossRef Medline

Schier LA, Blonde GD, Spector AC (2016) Bilateral lesions in a specific sub- 
region of posterior insular cortex impair conditioned taste aversion expression in rats. J Comp Neurol 524:54-73. CrossRef Medline

Schoenfeld MA, Neuer G, Tempelmann C, Schüssler K, Noesselt T, Hopf JM, Heinze HJ (2004) Functional magnetic resonance tomography correlates of taste perception in the human primary taste cortex. Neuroscience 127:347-353. CrossRef Medline

Shi CJ, Cassell MD (1998) Cortical, thalamic, and amygdaloid connections of the anterior and posterior insular cortices. J Comp Neurol 399:440468. CrossRef Medline

Simon SA, de Araujo IE, Gutierrez R, Nicolelis MA (2006) The neural mechanisms of gustation: a distributed processing code. Nat Rev Neurosci 7:890-901. CrossRef Medline

Singh PB, Iannilli E, Hummel T (2011) Segregation of gustatory cortex in response to salt and umami taste studied through event-related potentials. Neuroreport 22:299-303. CrossRef Medline

Smith DV, Travers JB, Van Buskirk RL (1979) Brainstem correlates of gustatory similarity in the hamster. Brain Res Bull 4:359-372. CrossRef Medline

Spector AC, Travers SP (2005) The representation of taste quality in the mammalian nervous system. Behav Cogn Neurosci Rev 4:143-191. CrossRef Medline

Stettler DD, Axel R (2009) Representations of odor in the piriform cortex. Neuron 63:854-864. CrossRef Medline

St John SJ, Boughter JD Jr (2009) Orosensory responsiveness to and preference for hydroxide-containing salts in mice. Chem Senses 34:487-498. CrossRef Medline

Tokita K, Inoue T, Boughter JD Jr (2009) Afferent connections of the para- brachial nucleus in C57BL/6J mice. Neuroscience 161:475-488. CrossRef Medline

Tokita K, Armstrong WE, St John SJ, Boughter JD Jr (2014) Activation of lateral hypothalamus-projecting parabrachial neurons by intraorally delivered gustatory stimuli. Front Neural Circuits 8:86. CrossRef Medline

Tokita K, Boughter JD Jr (2016) Topographic organizations of taste-responsive neurons in the parabrachial nucleus of C57BL/6 J mice: an electrophysiological mapping study. Neuroscience 316:151-166. CrossRef Medline

Travers SP, Norgren R (1995) Organization of orosensory responses in the nucleus of the solitary tract of rat. J Neurophysiol 73:2144-2162. Medline

Wu A, Dvoryanchikov G, Pereira E, Chaudhari N, Roper SD (2015) Breadth of tuning in taste afferent neurons varies with stimulus strength. Nat Commun 6:8171. CrossRef Medline

Xie K, Fox GE, Liu J, Lyu C, Lee JC, Kuang H, Jacobs S, Li M, Liu T, Song S, Tsien JZ (2016) Brain computation is organized via power-of-twobased permutation logic. Front Syst Neurosci 10:95. Medline

Yamamoto T, Yuyama N, Kato T, Kawamura Y (1985a) Gustatory responses of cortical neurons in rats. III. Neural and behavioral measures compared. J Neurophysiol 53:1370-1386. Medline

Yamamoto T, Yuyama N, Kato T, Kawamura Y (1985b) Gustatory responses of cortical neurons in rats. II. Information processing of taste quality. J Neurophysiol 53:1356-1369. Medline

Yamamoto T, Matsuo R, Kiyomitsu Y, Kitamura R (1989) Taste responses of cortical neurons in freely ingesting rats. J Neurophysiol 61:1244-1258. Medline

Yokota T, Eguchi K, Hiraba K (2011) Functional properties of putative pyramidal neurons and inhibitory interneurons in the rat gustatory cortex. Cereb Cortex 21:597-606. CrossRef Medline 